Archived version from NCDOCKS Institutional Repository http://libres.uncg.edu/ir/asu/

\title{
Appalachïan
}

B O O N E, N O R T H C A R O L I N A

\section{Seeing With Our Own Eyes: Youth In Mathare, Kenya Use Photovoice To Examine Individual And Community Strengths}

\author{
By: Emily K. Dakin, Sarah Noyes Parker, James W. Amell, and Brittany S. Rogers
}

\begin{abstract}
In this study, youth residents of the Mathare community of Nairobi, Kenya documented individual and community strengths using photovoice, a method that is grounded in the principles of community-based participatory research. Research was conducted in collaboration with the Mwelu Foundation, a youth-based participatory photography organization in Mathare. Template analysis was used to code the data, and industriousness, positive identity, community resources, and resilience emerged as the identified individual and community strengths. The project highlighted the value of photovoice for promoting empowerment and highlighting the perspectives of largely invisible populations. Implications of photovoice for social work research and practice are discussed.
\end{abstract}

Dakin, E. K., Parker, S. N., Amell, J. W., \& Rogers, B. S. (2015). Seeing with our own eyes: Youth in Mathare, Kenya use photovoice to examine individual and community strengths. Qualitative Social Work, 14(2), $170-192$. https://doi.org/10.1177/1473325014526085. Publisher version of record available at: https://journals.sagepub.com/doi/full/10.1177/1473325014526085 

strengths

\title{
Emily K Dakin
}

School of Social Work, Colorado State University, CO, USA

\section{Sarah Noyes Parker}

Ecumenical Refugee and Immigration Services, CO, USA

\section{James W Amell}

Department of Social Work, University of Minnesota-Duluth, MN, USA

\section{Brittany S Rogers}

Colorado Access, CO, USA

\begin{abstract}
In this study, youth residents of the Mathare community of Nairobi, Kenya documented individual and community strengths using photovoice, a method that is grounded in the principles of community-based participatory research. Research was conducted in collaboration with the Mwelu Foundation, a youth-based participatory photography organization in Mathare. Template analysis was used to code the data, and industriousness, positive identity, community resources, and resilience emerged as the identified individual and community strengths. The project highlighted the value of photovoice for promoting empowerment and highlighting the perspectives of largely invisible populations. Implications of photovoice for social work research and practice are discussed.
\end{abstract}

\section{Keywords}

photovoice, empowerment, young people, youth, Kenya, Africa

\section{Corresponding author:}

Emily K Dakin, c/o School of Social Work, Colorado State University, I586 Campus Delivery, Fort Collins, CO 80523-I586, USA.

Email: Emily.Dakin@colostate.edu 
These people who are in Mathare, they just have the potential but it seems like ... people are not considering us for our positives.

Quote by Abdi, youth participant in the Seeing With Our Own Eyes project

Within the city limits of Nairobi, Kenya are roughly 80 informal settlements, a more diplomatic word for the term slum (Gulis et al., 2004). Following Kenya's independence from British rule in 1963, several factors caused immigration from rural areas of Kenya to Nairobi, leading to the creation of these settlements. These factors included "migration during the struggle for independence, rural-urban migration and urban population growth without corresponding housing provision" (Mitullah, 2003: 11). The term "informal settlements" was coined in 1972, when plots of land were allocated to people who had been without land prior to independence. The use of these plots of land was considered informal squatting, and was technically illegal, as no land titles had been granted (Gulis et al., 2004). Because these informal settlements are illegal, the Kenyan government has generally not provided them with infrastructure and basic services such as electricity, water, health services, or law enforcement (Erulkar and Matheka, 2007). However, despite their deplorable conditions (Mitullah, 2003), roughly one-third of the citizens of Nairobi live in one of its informal settlements (Harding, 2002).

Mathare and Kibera are Nairobi's two largest and most notorious informal settlements. Mathare is a quick bus ride from the heart of the capital and the focal point for the research described here. A rough estimate is that approximately 800,000 people live in Mathare, an area approximately the size of New York City's Central Park (Harding, 2002; Kimutai, 2008). The term "slum" is used intentionally within this article out of respect for the Mathare youth participants in the Seeing With Our Own Eyes project, who themselves used this term with a sense of pride when reflecting on their community. The name, "Seeing With Our Own Eyes," comes from a common expression used by the participating youth to indicate that something was really true, as in, "It's true. I have seen it with my own eyes!" It is estimated that $32 \%$ of the residents of Nairobi's slums (including, but not limited to, Mathare) are youth 0-14 years old. This percentage is lower than the Kenyan national average of $47 \%$ and is likely attributable to the higher mortality rate for children residing in the slums (African Population and Health Research Center (APHRC), 2002b). Given the estimates for Mathare's overall population and the percentage of youth in Nairobi's slums, we roughly estimate that 256,000 children aged $0-14$ reside in Mathare.

While several studies (APHRC, 2002a, 2002b; Erulkar and Matheka, 2007; Kaim-Atterhog and Ahlberg, 2007) have focused on Kenya's informal settlements by identifying areas of concern, there is a lack of research examining strengths of these communities or exploring the perspectives of those living within them. More specifically, although youth make up a significant percentage of slum dwellers, little is known about their experiences growing up in these poor urban environments 
(Erulkar and Matheka, 2007). This study addressed this gap in the research by exploring life within Mathare from the perspectives of its youth with the goal of examining their perceptions of individual and community strengths.

\section{Theoretical framework for study}

The photovoice method (see "Methods" section below) used in this study is grounded in principles of community-based participatory research (CBPR). CBPR is a collaborative approach to research that equitably involves all partners in the research process and recognizes the unique strengths that each brings (Israel et al., 1998). The CBPR process begins by community members identifying an important research topic. Following topic identification, CBPR then seeks to increase our knowledge and understanding of the identified area of interest, followed by applying that knowledge and understanding to take action. Thus, CBPR is an empowering approach that enables researchers, community leaders, and community members to improve community well-being.

The CBPR approach to research is consistent with the empowerment concept inherent in strengths-based social work practice. Barbara Solomon pioneered work in the development of social work empowerment theories as a strengths-based approach to engaging with oppressed African American populations (Solomon, 1976, 1987). Solomon (1976) identified empowerment as a process "aimed at reducing the powerlessness stemming from the experience of discrimination because the client belongs to a stigmatized collective" (p. 29), and further indicated that empowerment can be a goal for individual, group, and community-level interventions. Empowerment occurs through the development of a view of self as capable and competent to use available resources to achieve goals (Solomon, 1976, 1987). Later developments in social work empowerment theories (e.g., Lee, 2001) expanded the focus from racial and ethnic minorities to a more general focus on individuals experiencing oppression. Lee (2001), building on Solomon's (1976) definition of empowerment, identified three interlocking dimensions of empowerment including developing a sense of self-efficacy, developing critical consciousness about the social and political environment, and developing resources, strategies, and competence for goal attainment.

\section{Methods}

\section{Project background}

The authors partnered with the Mwelu Foundation, a non-profit organization located in Mathare, to conduct this project. The Mwelu Foundation is a youthbased participatory photography organization in Mathare that works with youth to help them develop their potential through photography, documentary video, and journalism (Mwelu Foundation, 2014). The Mwelu Foundation specifically uses photography and documentary video to communicate the problems and 
desires of the Mathare community to a broader audience. It also hopes to "displace the myth that slums like Mathare are dead-end places with no potential or homegrown talent" (J Mwelu, 15 April 2009, personal communication). The organization's founder, Julius Mwelu, became involved in a participatory photography project as a teenager, which established his interest in becoming a professional photographer. Although the Mwelu Foundation's main programs involve photography, film, and journalism, it has also branched out into other community activities such as HIV/AIDS awareness, essential life skills training, computer training, and community cleanups. The authors learned about the work of the Mwelu Foundation, and because this organization's work is consistent with the goals of photovoice (see "Methods" section below), we contacted it to determine its potential interest in partnering around a photovoice project. The Mwelu Foundation expressed an enthusiastic interest in this partnership. Working with an organization that was already established and locally run helped the authors to more effectively navigate cultural barriers and to establish rapport with the participants.

Although our photovoice project was undertaken in collaboration with the Mwelu Foundation, it was a separate, distinct project from the Foundation's work. All of the photographs presented in this manuscript were taken by the youth participants in the photovoice project. The research team is from the United States and a member of the research team ( referred to throughout this article as the on-site research team member) traveled to Mathare with the specific goal of undertaking the photovoice research described in this manuscript. The research goals (i.e., identifying individual and community strengths) presented in this manuscript were posed prior to traveling to Mathare, and all the activities of the photovoice project (e.g., photography, SHOWeD discussion, community art presentation) were conducted to achieve the goals of the research project.

\section{Method overview}

This study used the photovoice approach to examine youths' perceptions of individual and community strengths in Mathare. Photovoice is a participatory qualitative research approach that involves providing cameras to community members so that they may visually represent their lived experiences to others (Lopez et al., 2005; Oliffe and Bottorff, 2007; Wang and Burris, 1997). The goals of photovoice are (a) for participants to document and reflect their community's strengths and concerns, (b) to promote critical discourse and knowledge about important community issues through group discussions and photographs, and (c) to provide a forum for the presentation of people's lived experiences through their own images and language (Wang, 1999; Wang and Burris, 1997). Although we worked with the youth participants in this project to identify community concerns, we placed a particular emphasis on individual and community strengths for two reasons. First, Mathare is often described by outsiders in terms of deficits, and the authors hoped that focusing on community strengths in this project would help provide a more complete, strengths-based picture of Mathare. Second, our study's youth participants were adolescents at a critical developmental stage of identity 
formation, when negative valuations from membership in a stigmatized community could be harmful to the development of a positive sense of self. This consideration also led us to emphasize community strengths with the goal of supporting positive identity development among the youth as members of the Mathare community.

\section{Participants}

At the time that the Seeing With Our Own Eyes project was conducted, the Mwelu foundation had approximately 30 youth participants, and there were 20 initial participants in the photovoice project. Of the 20 initial participants, two girls dropped out within the first two weeks but were replaced with two other male participants. One girl dropped out because she lost her camera and felt embarrassed to tell the on-site research team member, who learned of the reason via the Mwelu Foundation Director. Another girl dropped out due to competing family demands. Because the first two participants dropped out so early, they were not included in the data analysis. Of the 20 final youth participants, 12 were males and eight were females, with ages ranging from 12 to 19 years old, and from seventh grade through form four (equivalent to 12th grade in the United States). (See Table 1 for further detail about participant age and grade.) At the outset of the project, the 20 students divided into four small mixed-gender groups with five students in each group. Vacancies in the small groups were created when the two youth dropped out, and these vacancies were filled by the two youth who replaced them. The small groups were formed to keep the process more manageable, and the youth themselves determined the membership of the small groups to keep the research participant driven.

The use of the photovoice method raises concerns which, if not addressed, could create a risk for participants. Privacy concerns and the potential for falsely portraying a participant (positively or negatively) are important considerations in photography (Wang and Redwood-Jones, 2001). Recognizing these potential

Table I. Study sample ages and grades.

\begin{tabular}{ll}
$\begin{array}{l}\text { Number of } \\
\text { participants }\end{array}$ & Age and grade \\
\hline I & I2 years old, seventh grade \\
3 & I3 years old, eighth grade \\
5 & I4 years old, form one (equivalent to U. S. ninth grade) \\
5 & I5 years old, form two (equivalent to U.S. I0th grade) \\
3 & 16 years old, form three (equivalent to U.S. I I th grade) \\
2 & 17 years old, form four (equivalent to U.S. I2th grade) \\
I & 19 years old, not in school \\
\hline
\end{tabular}


concerns, the youth were taught who and what they could photograph and how to photograph safely. Photovoice research also presents ethical considerations as "it would be untenable to spur a false sense of empowerment where there is no opportunity for meaningful participation" (Wang et al., 1996: 1398). Ultimately, photovoice research can create an impact that will continue after the researcher has left. The implications of a photovoice project, including long-term goals and other possible outcomes, should be addressed prior to the start of a project. To support long-term positive change through this photovoice project, all revenues generated by this project through photography exhibits are being diverted back to the Mwelu Foundation for the benefit of the foundation and its participants.

\section{Procedures}

Human subjects' approval for the study was obtained from the Colorado State University Institutional Review Board (IRB) prior to data collection. We developed youth assent, youth consent (for any youth age 18 or older), and guardian consent documents for the project, with the goal of obtaining assent from the minor youth (age 17 and younger), consent from youth age 18 or older, and consent from a minor youth's guardian. The assent and consent documents clearly indicated the plan to present and publish the results of the research. These documents also specifically indicated that each youth had a choice about what pictures, if any, she or he would like to have included in a presentation or publication and also whether or not she or he would like to have her or his name associated with photos or quotes from the project. The assent form additionally provided an area for each youth to indicate whether or not he or she would like to have his or her name associated with any pictures or quotes from the project. The assent form was written below a 6th grade level of readability, and the consent documents were written below an 8th grade level of readability. Because the minor youth were very excited about the project, they also wanted to read and sign the consent document, and they were allowed to do so. Because of the readability of the assent document, we ultimately asked the one adult youth to sign it as well as the consent document. The on-site research team member verbally (in English) described the assent and consent documents to the youth in addition to the youth reading these documents themselves. Julius Mwelu, the founder of the Mwelu Foundation, was present during this process, and we considered the larger sociopolitical context in this decision. Julius Mwelu is a known and trusted adult to the youth participants in the Mwelu Foundation. Given this, we believed that these youth would experience a greater sense of safety in engaging in this research if he was present during the assent/consent process than if this process occurred with only a white, Western member of the research team present. Another important reason for Julius's presence during this process was to help with translation if needed. The youth had an opportunity to ask any questions about the assent and consent documents, and they felt they understood the documents well. In going through the assent/consent process, each youth participant was provided with two copies of the assent and 
consent forms, including one copy to sign and return and one copy to keep for future reference. Through these efforts, the youth clearly understood the purpose of the project, what participation in the project would involve, that participation in the project was entirely voluntary, that they could choose to drop out at any time, and that they had the ultimate authority regarding use of their quotes and photographs. Thus, every youth in the project, regardless of age, signed both an assent and consent document, and all youth clearly expressed the desire for their name to be associated with quotes and photographs in a presentation and publication from the project.

All the youths' parents had previously consented to their participation in the activities of the Mwelu Foundation. For this reason, and also because the youths' parents and guardians often had less formal education than their children, Mwelu Foundation founder Julius Mwelu believed it to be more appropriate for him to sign the consent forms on behalf of the youths' parents. Therefore, consent on behalf of every youth participant (including the 19-year-old participant) was obtained from Julius. In addition, verbal consent was obtained by Julius Mwelu at the outset and repeatedly throughout the process from every youth's parent or guardian. In addition to this, Julius Mwelu also repeatedly obtained assent from the youth themselves both verbally and via email. When the research team returned for the member check group, all the youth verbally agreed, with Julius Mwelu present, that their photos and quotes could be used in association with their names in a publication. Although the youth expressed their desire to have their full names given in association with their photos and quotes for a community presentation and publication from this project, to protect the youth, the project team felt it was preferable to use their first names only.

The photovoice groups met twice weekly for seven weeks. In the first meeting of the week, the youth were given a lesson on photography and received an assignment for that week. They then used the intervening time between this meeting and the second meeting to take their photographs. During the second meeting of the week, the youth shared and discussed the pictures that they had taken, and they also began charging their cameras' batteries for the next week. In the initial orientation to the project (week one), the youth were given the instruction to take pictures of Mathare. This assignment oriented the youth to the photovoice approach, and their initial photographs additionally familiarized the on-site research team member with Mathare. Following this orientation, the youth were given assignments that involved documenting various community strengths. These included assignments such as to take pictures:

- of things you like about Mathare

- that show off the slum

- that show the lifestyle in Mathare

As part of the effort to document community strengths, the youth also discussed why they like living in Mathare. After starting with the broad topics identified 
above, each group also selected particular topics to focus on, which included religion, water taps, small businesses, food, education, and healthcare.

At the beginning of each discussion about that week's photography assignment, each participant selected 15-20 pictures that he or she wanted to discuss from her selection of photos taken that week. Discussions about participants' photos occurred in a group setting facilitated by on-site research team member, and participants were also encouraged to contribute and ask questions. The on-site research team member asked clarifying questions throughout the group discussion as a form of member checking, to assess whether participants' views were being accurately understood, and to give participants an opportunity to provide feedback, or to revise or retract previous statements. The on-site research team member also took field notes containing methodological reflections and suggestions during each discussion, and then reviewed these notes following each discussion. The review of field notes after each discussion helped to identify clarifying questions to ask during the next group discussion, thereby providing further opportunity for participant involvement in the analytic process.

The photo discussions were guided by the use of a Freirean-based critical dialogue technique called SHOWeD that helped the youth identify, reflect, and act on community strengths and concerns. The SHOWeD method involves a series of questions used to guide discussion from a personal level to social analysis and action steps (Wallerstein and Bernstein, 1988). SHOWeD questions include: What do you see here? What's really happening here? How does this relate to our lives? Why does this situation, concern, or strength exist? What can we do about it? Although the SHOWeD method was not strictly followed, it provided a useful means of moving participants from simply visually documenting their community to beginning to critically reflect on sociopolitical issues and social change possibilities. For example, using the SHOWeD technique, one group that wanted to focus on documenting Mathare's water taps was guided in discussion about problems related to the water taps (e.g., there are not enough water taps; people steal parts from the water taps, causing them not to work), strengths related to the water taps (e.g., the government installs them for free; the water is free), how water taps related to their lives (e.g., water taps allow them to remain clean; girls stated that they go to water taps daily after school to fetch water), what could be done about water taps (e.g., more could be installed; there could be a way of keeping watch over the water taps so that they are not stolen), and what they would suggest to the government in order to make changes to water taps (e.g., they could communicate to the government how important the taps are for them).

\section{Data analysis}

Each photo discussion session was audio recorded, and these audio recordings were subsequently transcribed for data analysis. Because English is a national language in Kenya, these photo discussions were conducted in English. Therefore, the transcriptions are verbatim, rather than translated. English was generally the second or 
third language spoken by the participants, which accounts for the distinctive language in the transcriptions and quotes reported here.

A template analysis was performed using the photo discussion session transcriptions. Template analysis is a qualitative data analysis method, typically used in studies with 20-30 participants, in which an initial "template" or coding structure is developed and refined over multiple successive iterations (Brooks and King, 2012; King, 2004). The template development and analysis process is complete once a final template has been created in which themes have been identified for all sections of the transcripts that are relevant to a study's research questions (King, 2004). A final coding template was arrived at in this study after five successive template iterations. The on-site research team member returned to Mathare six months after completing the initial data analysis to conduct a follow-up member check group with the goal of assessing the credibility of this analysis. Eighteen of the 20 participants attended this member check session. Initial data analysis results, photos, and quotes were shared at this session, and participants were given an opportunity to provide feedback about the analysis. All participating youth in attendance expressed agreement that the results accurately reflected their views and that they did not want any aspect of the analysis to be changed. They also reaffirmed their wish for their names to be associated with photographs and quotes in a publication from the project.

\section{Results}

In this section, we report themes pertaining to individual and community strengths. While our focus was on strengths, we also report on identified concerns, which often represented the reverse or flip side of the identified strength. The below themes were present across the four small groups and were identified by most or all of the youth participants.

\section{Industriousness}

The industriousness theme included group discussion data and photographs reflecting the notion that Mathare's harsh climate necessitated being able to accomplish much with few resources. One aspect of the industriousness theme was the youths' belief that Mathare residents are very hardworking. The youth particularly disputed stereotypes held by outsiders that Mathare residents are lazy, so the industriousness theme was a counter to their concern about negative stereotyping by outsiders. Indeed, many Mathare residents were identified as small business owners selling products such as fresh produce, nuts, prepared foods, and household items at small kiosks. Also inherent in the hardworking spirit of Mathare residents was the concept of "struggling," which the youth used in a way that had positive connotations, indicating a person who has a very strong work ethic. This concept was often verbalized when discussing pictures of kiosks or small businesses and pictures of younger people working. The industriousness theme also included 


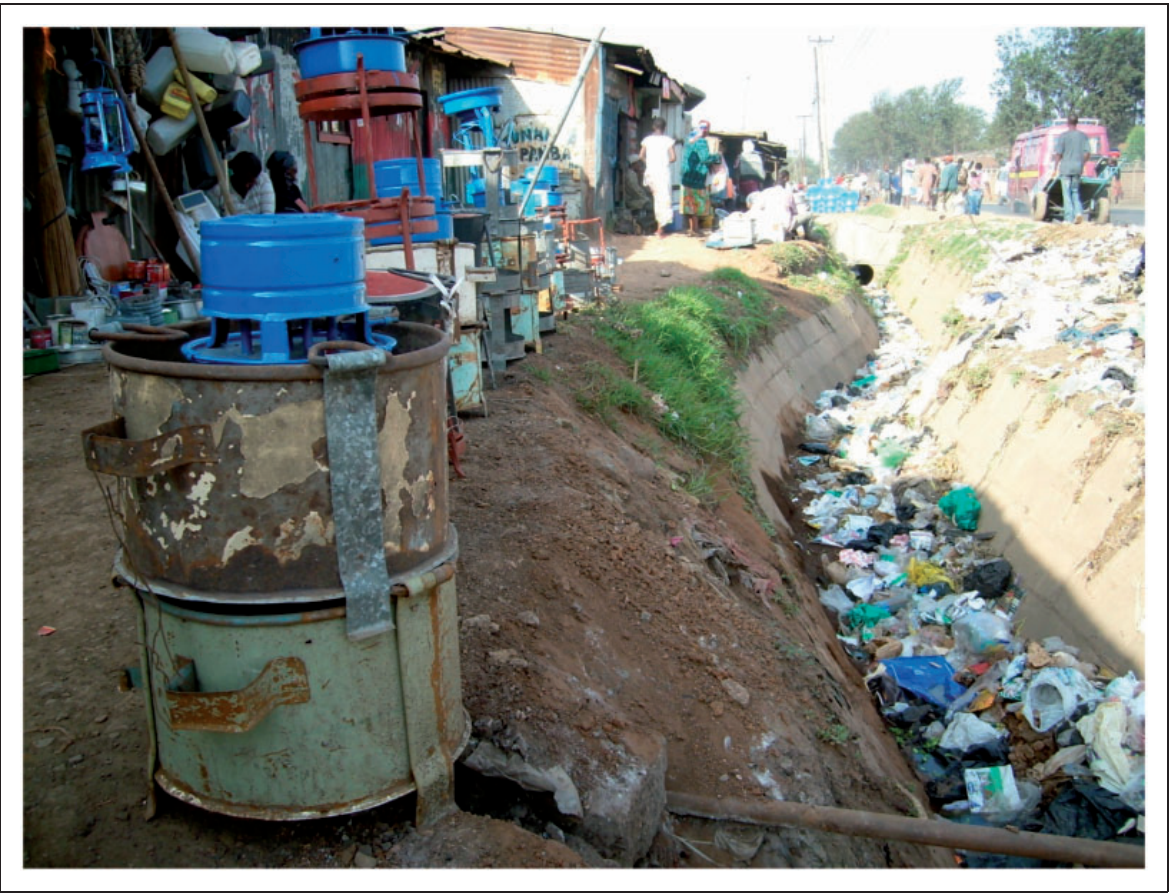

Figure I. Giko by Jeff. Old paint tins reprocessed into coal cookers called gikos. Jeff wanted to illustrate the resourcefulness and creativity of Mathare community members in making and selling products despite high levels of poverty.

family members working together to generate more income. A final aspect of the industriousness theme was resourcefulness and creativity, defined as the ability to make products with one's hands or to salvage and recycle old products into new ones, such as reprocessing old paint tins into coal cookers called gikos (see Figure 1). The creative use of available resources allowed residents to generate more work for themselves through recycling and cleverly repurposing materials found in the community. One Mathare youth, Jeff, expressed the notion of creativity and resourcefulness by stating in reference to Figure 1:

I was trying to point out that although the people here live in poverty and all that, they still have the courage and even determination to sell and make things by themselves.

\section{Positive identity}

Another theme expressed by the youth addressed their positive identity as Mathare residents. Rather than being ashamed of living in Mathare, these youth expressed 
feeling proud of where they came from and lived. The youth often even used the term "slum" with a sense of pride when talking about Mathare. Expressions of pride frequently emerged when youth talked about photos of their families, homes, schools, and the Mwelu Foundation building. For instance, while talking about the homes of Mathare, another youth, Grace, stated:

Yeah, in Mathare we stay in good houses. Even though they are tin houses, they are good, and [are] good enough for us to stay in.

Moreover, the youth expressed a sense of pride about living in Mathare as it represented a connection to their families. Grace further stated:

I love Mathare because this is where I was born and this is where my mother was also born. Now, nobody can tell me to shift [move] from Mathare because this is my home.

The youth also voiced a layered perspective regarding life in Mathare. While one youth, Maxwel, indicated that there are difficult aspects of living in Mathare, he added (see Figure 2) that:

there are other places where there are worse things, like those [communities] that don't have water.

The participating youth expressed a sense of pride about their community while also acknowledging their concern about negative views of Mathare held by outsiders. According to another youth, Abdi:

What I can just say is that people really talk negatively. They really look at Mathare as a place where thugs come from, a place where criminals are situated, [and] a place of poverty. But the thing is, these people who are in Mathare, they have the potential. But it seems like people are not observing what they are doing... people are not considering us for our positives.

A final aspect of positive identity was having a strong sense of purpose. The participating youth expressed the belief that God had put them in Mathare for a reason, and therefore that they had a purpose in life. As Abdi explained:

Every person has a purpose as to what God has planned for him or her, so these children are the future of this world. They should be handled with care and support.

Having a sense of purpose was a source of strength for the Mathare youth, who believed that they could make a difference and that that they had a responsibility to contribute to their family and community. 


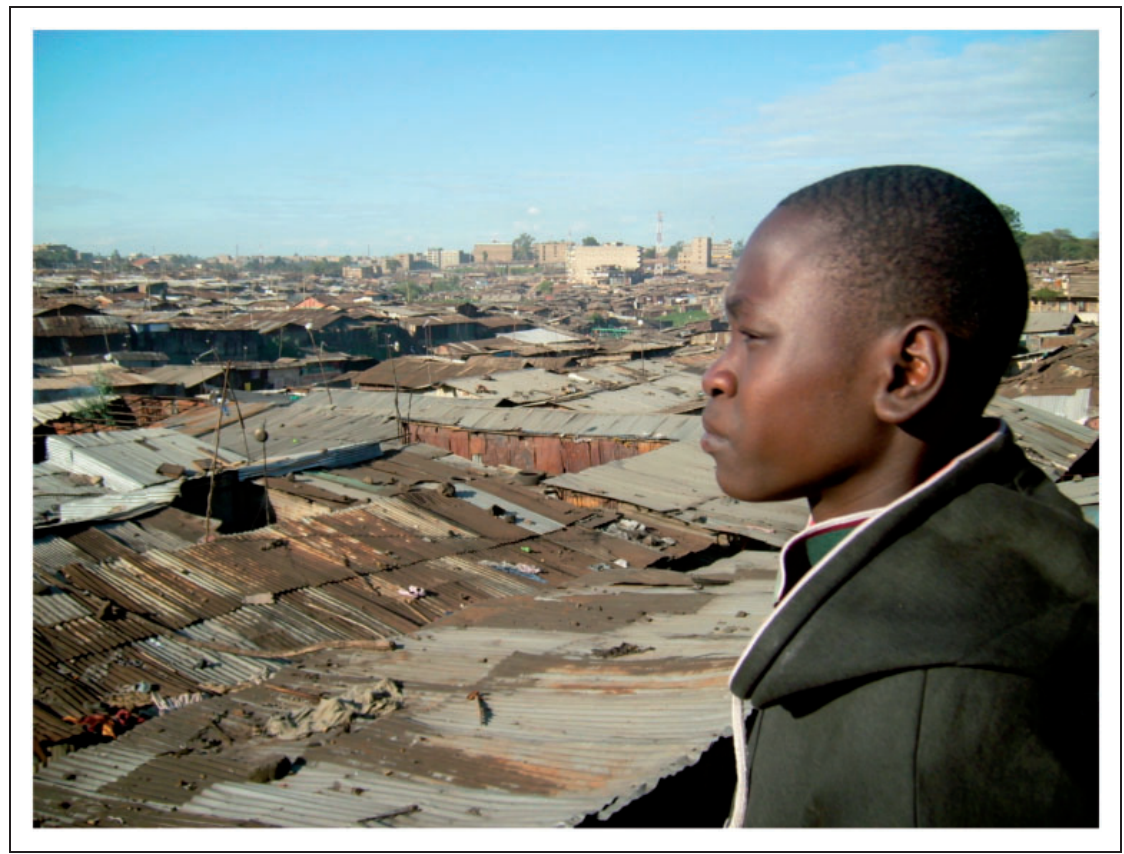

Figure 2. View of Mathare by Maxwel. Several youth, including Maxwel in the photo, expressed a sense of pride about living in Mathare, although they also acknowledged that many "outsiders" view the area as a place of poverty and crime. Despite their living conditions, youth associated their community with a sense of identity and generally characterized Mathare positively. Note: Maxwel expressed the desire for his image to be included in any publications coming from this project.

\section{Community resources}

Much of what the Mathare youth expressed in their photography and group discussions concerned resources within Mathare. They documented and described numerous organizations that served youth, addressed the environment, and promoted a higher quality of life in Mathare. The education available to the Mathare youth was viewed as a community resource, means for success, and way of instilling the strong work ethic that the youth associated with their community (see Figure 3).

Although these youth reported that community outsiders typically believed that Mathare community members lacked electricity, all the youth who participated in the Seeing with Our Own Eyes project stated that they had some sort of electricity available in their homes - usually one small light bulb hanging from the ceiling. For example, Jeff, in reference to Peter's photograph of electrical connection boxes in Figure 4, stated:

This is to show how electricity is now even going up to houses in the slum. 


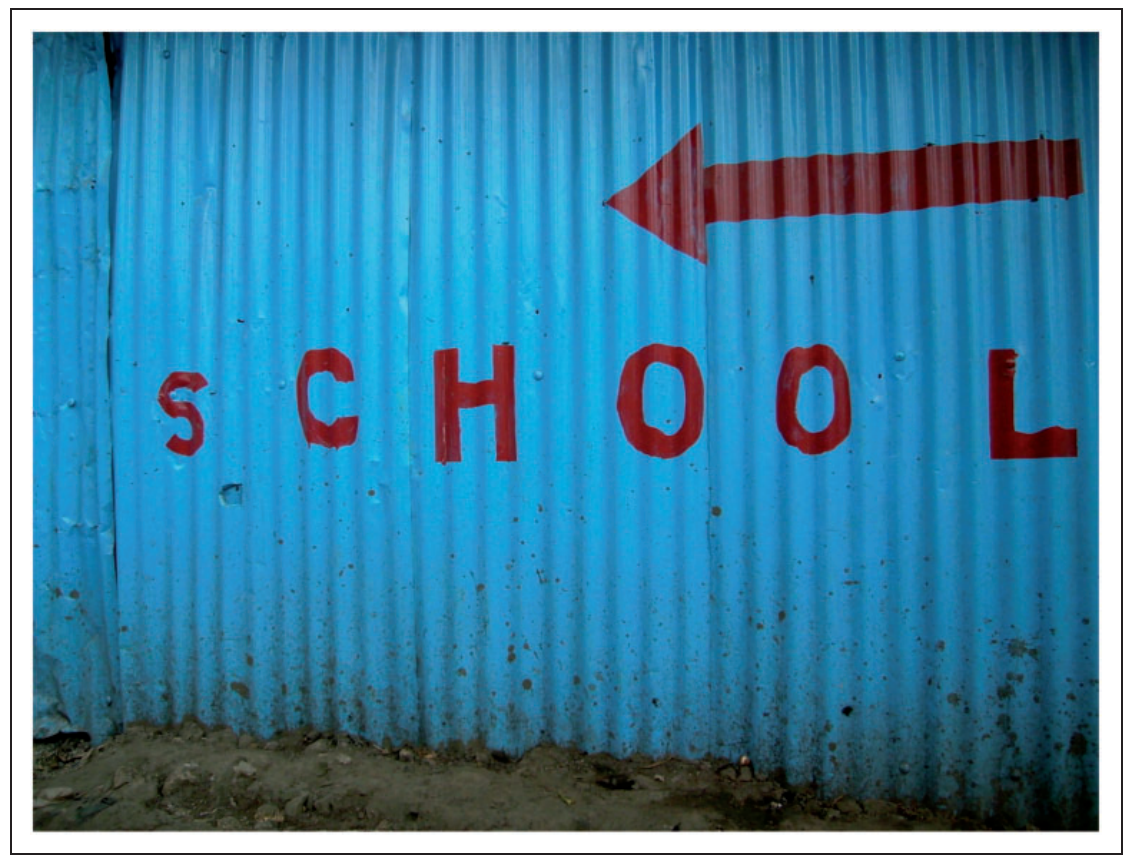

Figure 3. The Way to School by Moses. Many youth indicated that they felt fortunate to have access to a variety of resources in their community, including access to education. The youth also believed that other resources such electricity, health clinics, and the internet may be unrecognized by outsiders to their community.

The reduced cost or free health clinics and free HIV testing and counseling centers were also cited by the youth as examples of community resources. Moreover, at the time of this research project, efforts were underway to install a fiber optic cable that would provide internet connectivity. When describing a picture of the fiber optic cable that was being installed for internet service, Jeff, one of the most technologically savvy participating youth, stated:

This is a fiber optic cable they are laying. It really makes me happy when I'm seeing this, knowing we'll be connected to the internet very soon. So, even here in Mathare we will not be left out. [This is] really nice.

In addition to concrete resources, the youth expressed in their photographs and group discussions feeling a sense of freedom from living in Mathare due to its general lack of restrictions. They also indicated that living in Mathare enabled them to access to valuable opportunities, including the opportunity to participate in the photovoice project. 


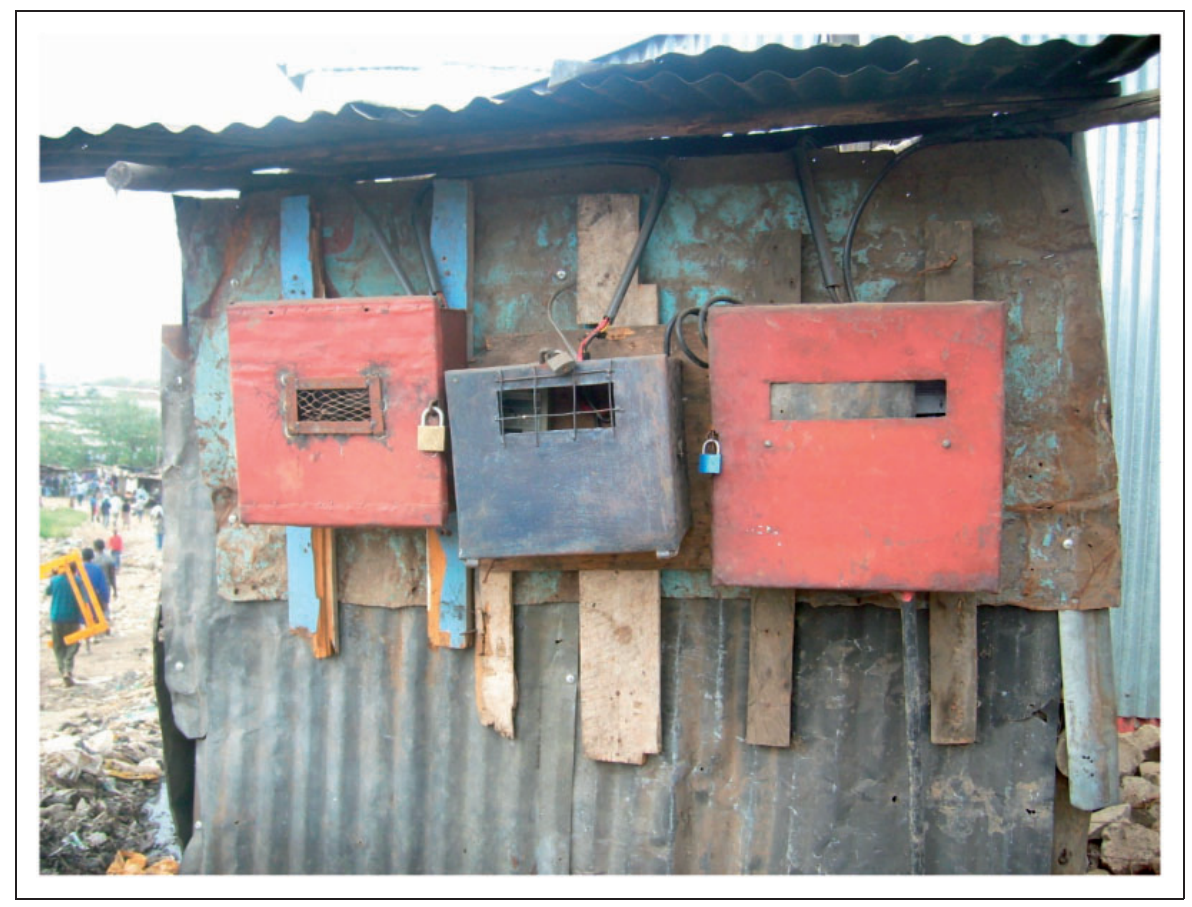

Figure 4. Electrical Connection Boxes by Peter. Electrical connection boxes, such as these shown in the photo, are more common in Mathare than many outsiders believe, according to the youth.

An interrelationship between strengths and concerns was sometimes evident in the Community Resources theme. For example, the youth identified government efforts to install more free water taps as community strength. However, while the youth identified the free water taps as a community strength, they also identified concerns related to these water taps, for example, that there were not enough water taps, or that these taps were sometimes not functional because of Mathare residents stealing parts from them.

\section{Resilience}

The concept of resilience was expressed by the youth through the idea that they were able to survive in the harsh environment of Mathare, a setting that would pose a great challenge to community outsiders. During one of the photo discussions, the youth generated a list of strengths about Mathare. During this discussion, many of the youth implicitly expressed the concept of resilience (see Figure 5). Again, this theme reflects a strengths-oriented frame on what could also be 


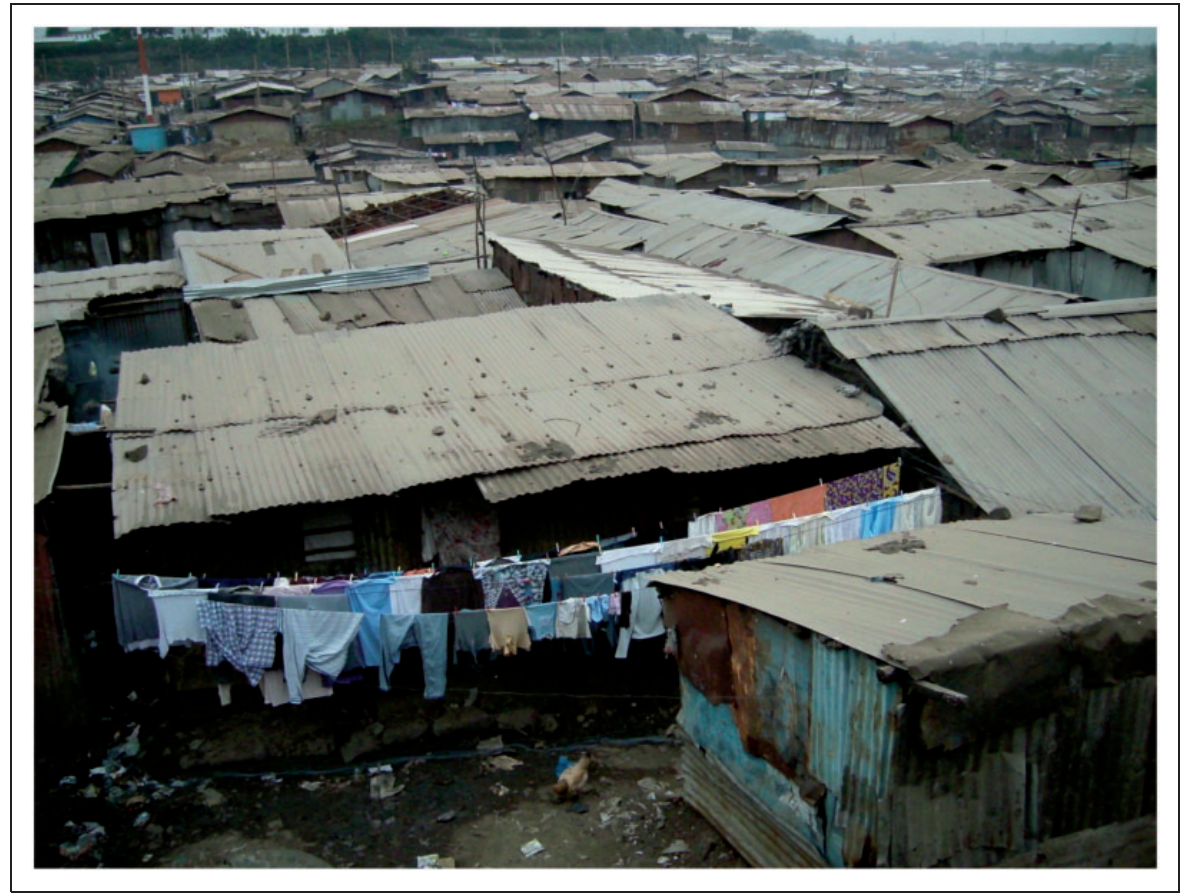

Figure 5. Home by Stephen. The youth acknowledged difficulties about living in the "harsh environment" of Mathare, but they continually referenced the resulting strength and resilience of community members who had survived under these circumstances.

understood in terms of a concern, namely, that Mathare is a harsh and challenging climate in which to survive. For example, Abdi stated:

These people of Mathare they are like - they survived through all this... They have survived all these troubles.... So, Mathare has really made the people here grow-it has made them to be 'man'. We are meant to suffer. They have experienced the suffering, [and] it has helped them to become used to the place as it has helped them. This has helped in making them not weak. It makes them strong.

\section{Project outcomes}

The work of the Mwelu Foundation, including this photovoice project, resulted in a community exhibit, multiple newspaper articles, international radio and television news coverage, and a feature on the national nightly news. A book from this project (Mwelu Foundation and Africalia, 2013) has been published, and proceeds generated by the book are benefitting youth participants of the Mwelu Foundation. Photos from this project were also featured in an exhibit 
at the 23rd session of the UN-HABITAT'S Governing Council ${ }^{1}$ in Nairobi, Kenya. In particular, the community exhibit functioned as the project's forum that is specified as a goal of photovoice projects (Wang, 1999; Wang and Burris, 1997). Although political leaders did not attend the community exhibit, it was well attended by Mathare community members, the local television news covered it, and it was also featured in the local newspaper. Although no direct social action resulted from the community exhibit (discussed further as a limitation below), the community exhibit and other forms of publicity from the project have helped to raise awareness about Mathare and to generate funds to support the Mwelu Foundation.

The identification of individual and community strengths, and the community exhibit and media attention that the project has generated, also reinforced to the participating youth that they, their project, and their community are important; these are different messages than these youth typically receive about their value as Mathare residents. Furthermore, involvement with this project helped to generate a sense of self-efficacy among the participating youth by reinforcing the notion that their efforts could be linked with a larger purpose (see Figure 6). Reflecting on this idea, Peter, speaking about the Mwelu Foundation, stated:

This is a positive thing ... This [is] very positive so that even journalists [can] come from the slum. Now they are not children at all but young photographers.

Aspects of empowerment experienced by Mathare youth are consistent with findings by Foster-Fishman et al. (2005), who also documented empowerment outcomes resulting from participation in a photovoice project. The empowerment outcomes identified in this project are similarly consistent with most of the dimensions of empowerment identified in the Critical Youth Empowerment Model developed by Jennings et al. (2006).

Now, several years after the completion of the photovoice project, nearly all of the participating youth are still enrolled in or have graduated from high school. Proceeds generated by the project have raised enough funds to cover all the participating youths' school fees, which most parents cannot afford to pay. Graduation from high school is highly unusual in this community, and seven MWELU Foundation youth graduated from high school in 2013. In addition to the concrete financial support, we believe that the youths' empowerment gained through participation in this project encouraged their continued enrollment in school. This is an especially important outcome for the project's female participants because it is not common practice for girls in Mathare to continue their education past the primary level.

A challenge for this project was to focus on community strengths while taking care to not gloss over areas requiring social action. Potential areas for social action naturally emerged during the SHOWeD discussion process. Furthermore, the 


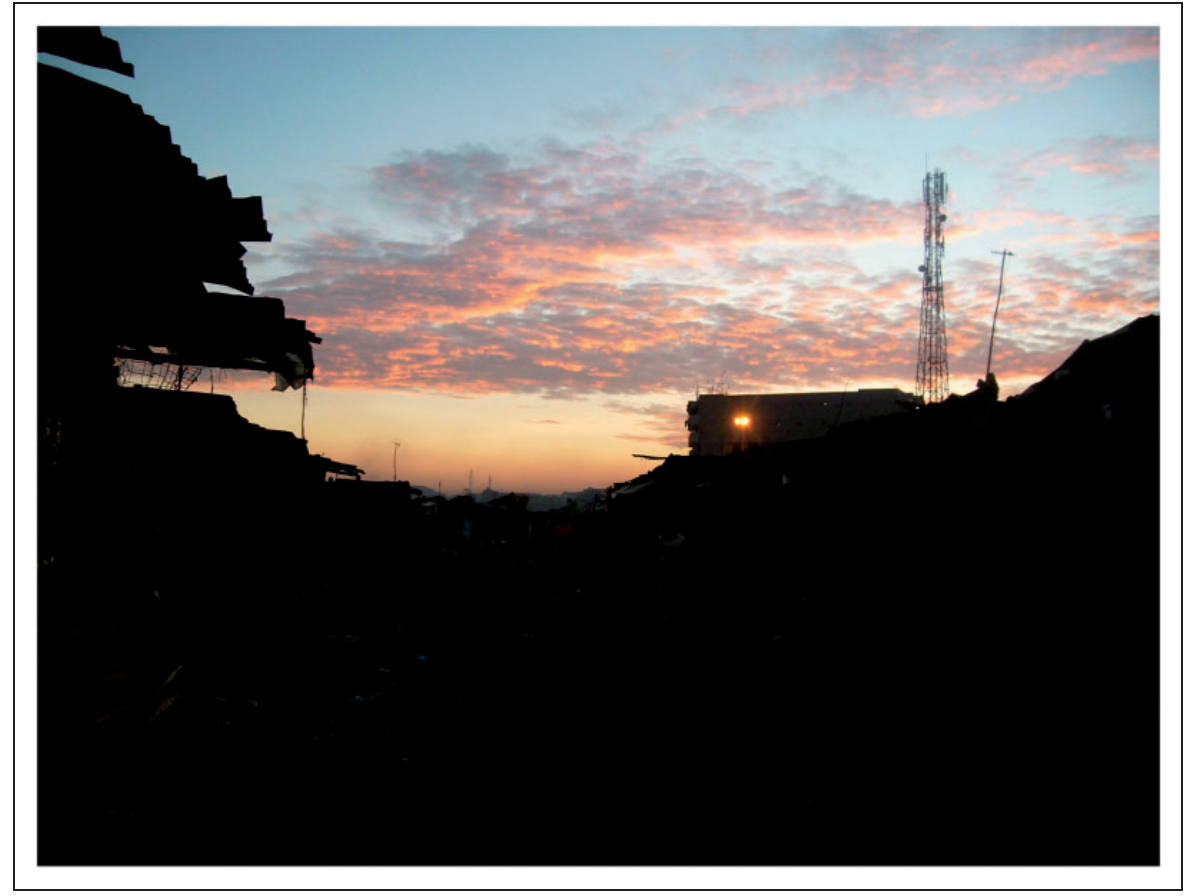

Figure 6. Sunset over Mathare by Antony. The Mathare youth participants in the Seeing With Our Own Eyes photovoice project described their empowered senses of self and the potential for utilizing their photography skills to strengthen the community of Mathare.

youth participants expressed the desire to use their photography skills to strengthen the Mathare community as a whole. As one participant, Stephen, stated:

My vision for joining Mwelu Foundation is to be a professional photographer and to raise up the problems which surround Mathare slum through pictures.

When discussing their photographs, the youth were asked, "If this photo were going to have a message, what would the message be?" Their responses addressed how they believed these photographs could generate social action to bring about social change. For example, Leila, in discussing the photo in Figure 7, stated:

I think they [government officials] should do something here in Mathare. They always say they'll 'change Mathare, change Mathare'. But, we've never seen it. So, if they just sit down and look at these photos, they'll have goosebumps in their stomach. And, they'll have to come and look at how they can help us in Mathare. ... They don't want the outside countries to see this kind of place ... So I think this photo... I would actually just take it to the President's office and ask 


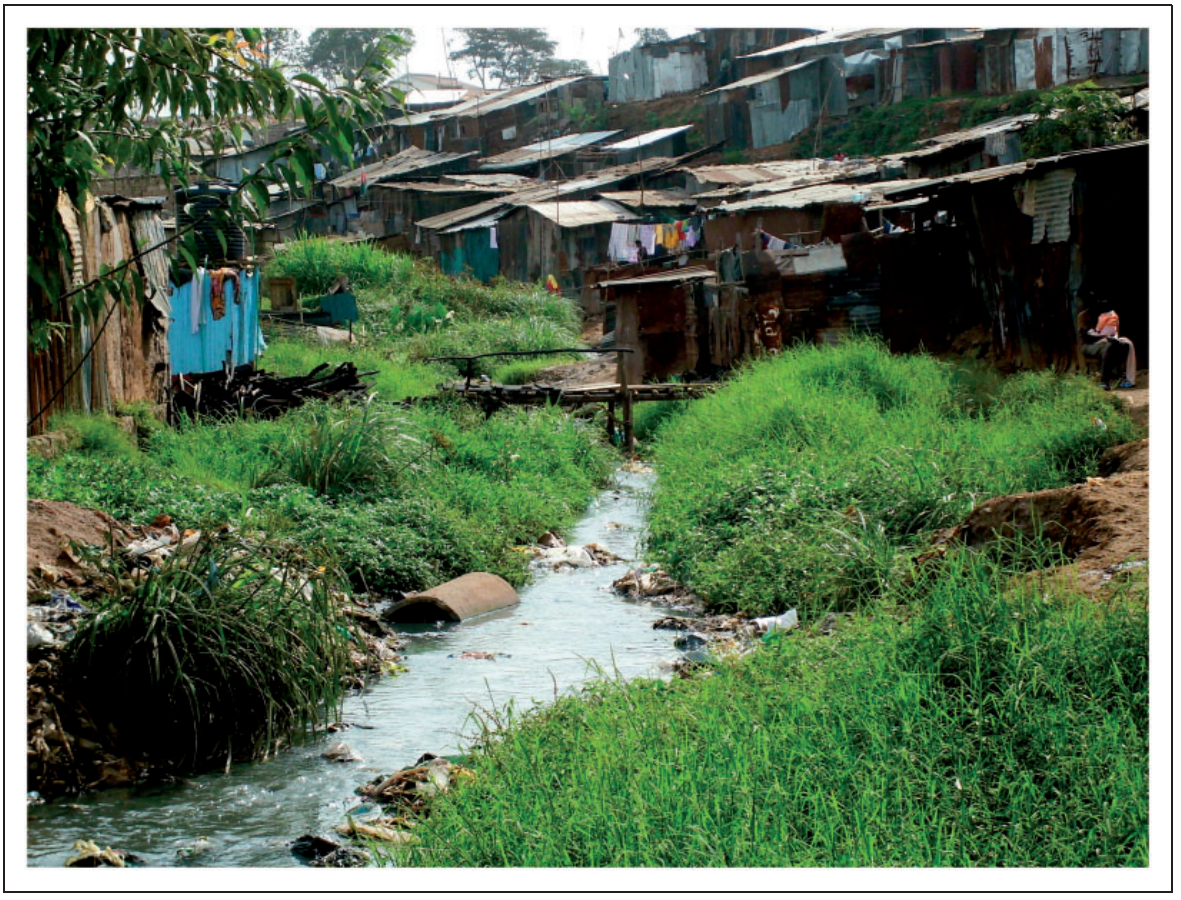

Figure 7. Mathare's Stream by Leila. When asked to describe the messages conveyed by their photographs, some youth indicated that their photographs were calls for social action. For example, Leila expressed the desire for this photograph to cause the Kenyan President to distribute financial aid to the region.

him if the money he gets, can he not distribute to his MPs [prime ministers] and [instead] help us in Mathare.

Leila seemed to be suggesting that seeing the conditions of Mathare visually depicted in a photograph could stir desire in government officials and others to change and improve conditions in this community. In her view, a photograph has the potential to generate an emotional call to action in a way that words alone cannot. On the other hand, the youth also sometimes expressed a sense of helplessness about being unable to respond to those in need. For example, Moses, in describing the photo in Figure 8, stated:

This photo is really depressing because you can see this boy [on the left] has the basic needs that children and others want. But now if you see here this boy [in the river] is trying to walk the river so that he can get at least 10 shillings [by picking up plastics and selling them] to buy food in the hotel, which will not be enough. And this boy 


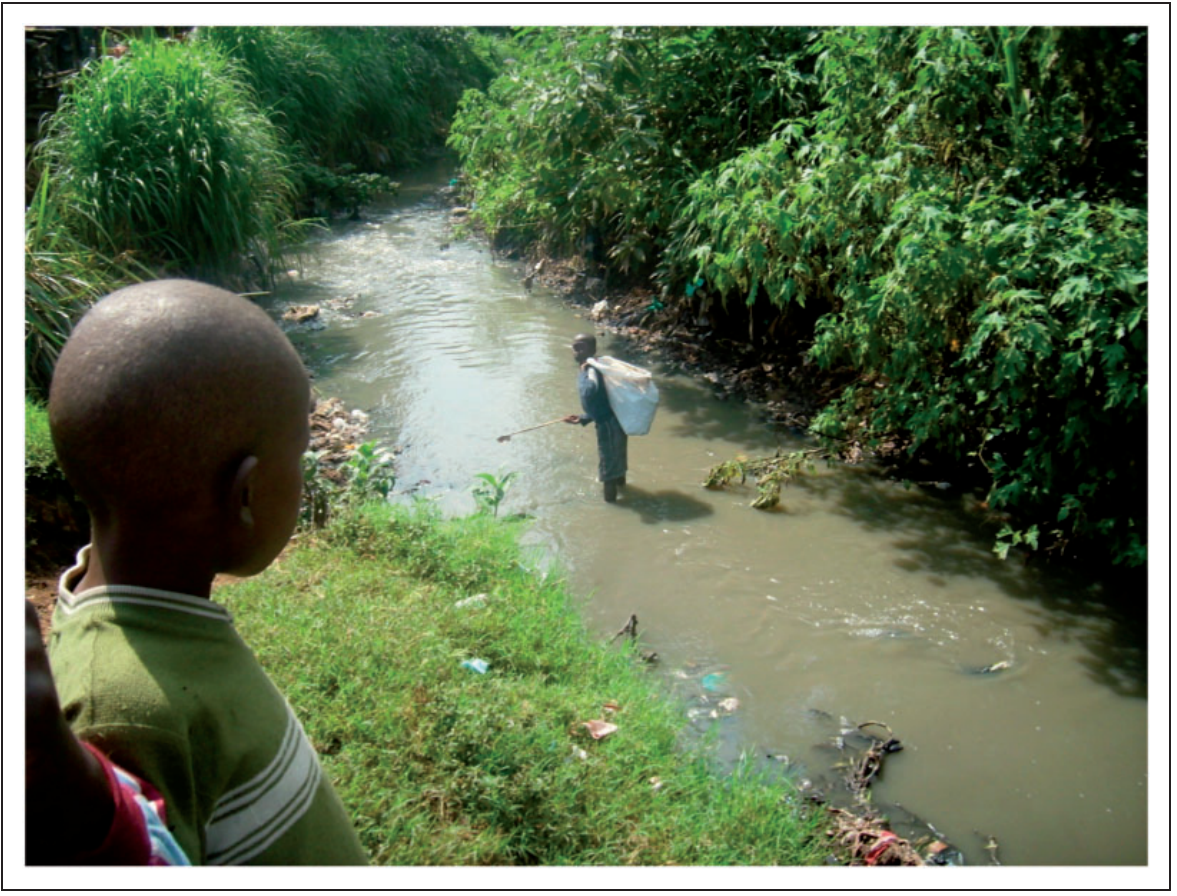

Figure 8. Picking for Metals by Moses. The Mathare youth also communicated a level of frustration about the lack of resources available to help others in their community. For example, in this photo, Moses says he was trying to capture the relationship between two boys, one boy standing in the river in need of help, and another boy watching him and unable to help. Note: the boy in the river is unidentifiable because of the distance and because his image has been blurred, while the boy standing to the side is unidentifiable because his face cannot be seen.

[on the left] looks on. To him I think he is thinking now in his heart, 'I wish that I had, I wish that I was great, I could have helped this boy.' But he is not great.

To follow-up on Moses's point, the research team member asked Moses about what he had been thinking about when he took the picture, and Moses responded:

I was thinking that if I take the photos of these two it will show the world that many people are willing but they cannot. That many, they want to help, but they cannot. They cannot get the help.

The social action goals of the project were primarily identified by the older youth, who represented approximately half of the youth participants in this project. The complexity of linking individual and group circumstances with broader 
sociopolitical issues may be better suited for older youths' level of cognitive development. Wilson et al. (2007) have similarly discussed the challenges that younger adolescents face in moving toward critical discourse and social action in a photovoice project.

\section{Discussion}

The Seeing With Our Own Eyes project demonstrates the value of using a photovoice approach in social work research that seeks to highlight the perspectives of largely invisible individuals and communities and to promote individual and collective empowerment. As a qualitative research method with a small sample, it is not possible to assume generalizability of this study's findings outside of Mathare. Future research could shed light on whether the identified individual and community strengths are also relevant to adult Mathare residents, to other informal settlements of Nairobi such as Kibera, or more broadly to informal settlements in Africa or other parts of the world. The significant individual and community strengths identified through this research speak to the importance having a strengths orientation when undertaking research within any impoverished community. The youth participants' identification of numerous community resources additionally reflects the strengths perspective principle that all environments are full of resources (Zastrow and Kirst-Ashman, 2010).

This study affirms the value of using photovoice as a CBPR method in developing countries and suggests the potential value of photovoice for social work practitioners intervening at group and community levels. For example, photovoice can provide an emotionally powerful means for consciousness-raising within communities and it has the potential to promote community member-identified social action and change efforts (Molloy, 2007). Photovoice research can also provide a mechanism for accessing the media and influencing policy within communities that do not have the resources to pay for a lobbyist (Molloy, 2007). The media coverage about the Seeing With Our Own Eyes project certainly demonstrates the potential media impact that a photovoice project can generate.

Two interrelated potential limitations of the project are that we placed a greater emphasis on community and individual strengths than on community concerns, and that the project did not result in direct social action outcomes. Highlighting community strengths may have limited the potential social action outcomes by placing less emphasis on areas needing social change efforts. On the other hand, as indicated above, limited social action outcomes have also been noted with other photovoice projects with youth (Wilson et al., 2007). Despite the lack of direct social action outcomes, we are hopeful that the significant attention that this project has generated through the various exhibits, the book about the Mwelu Foundation (Mwelu Foundation Africalia, 2014), and this article will increase awareness about Mathare that will lead to greater government efforts on its behalf. Additionally, as noted above, this project has also benefitted the participating youth through important educational and empowerment outcomes. 
In one sense, perhaps the positive identity theme and empowerment outcomes can themselves be seen as a form of social action resulting from this project.

The youth of Mathare are among its greatest strengths. Their belief in themselves, their desire to create change, and their identity are all inextricably linked to this place they call home. The photovoice approach used in the Seeing With Our Own Eyes project allowed us to identify significant individual and community strengths - industriousness, positive identity, community resources, and resilience - from the perspective of Mathare's youth. The Seeing With Our Own Eyes project illustrates the value of photovoice for illuminating participant views of community, revealing individual and community strengths, and empowering participants and their communities. The hope and optimism expressed by the Mathare youth participants in this photovoice project suggests that they will be able to positively impact the future of their community. This pronouncement was best expressed by Antony, a Seeing With Our Own Eyes project participant, who poignantly stated:

(While) I do find it difficult to be in the slum because of its environment and daily life, I believe that one photo will save the slum and I wish it to be mine.

\section{Acknowledgments}

The authors would like to acknowledge contributions from Jim Banning, PhD, Louise Jennings, PhD, Julius Mwelu, and all the youth participants in the Seeing With Our Own Eyes photovoice project.

\section{Note}

1. The United Nations Human Settlements Programme, UN-HABITAT, is the United Nations agency for human settlements. The Governing Council provides recommendations concerning the UN-HABITAT's policies and budget.

\section{References}

African Population and Health Research Center (APHRC) (2002a) Health and Livelihood Needs of Residents of Informal Settlements in Nairobi City: Occasional Study Report 2002. Nairobi, Kenya: Author.

African Population and Health Research Center (APHRC) (2002b) Population and Health Dynamics in Nairobi's Informal Settlements. Nairobi, Kenya: Author.

Attride-Stirling J (2001) Thematic networks: An analytic tool for qualitative research. Qualitative Research 1: 385-405.

Brooks J and King N (2012). Qualitative psychology in the real world: The utility of template analysis (Unpublished paper). Presented at the British Psychological Society Annual Conference, London, UK. Available at: http://eprints.hud.ac.uk/13656/(accessed 19 February 2014).

Erulkar AS and Matheka JK (2007) Adolescence in the Kibera Slums of Nairobi Kenya. Nairobi, Kenya: The Population Council. 
Foster-Fishman P, Nowell B, Deacon Z, et al. (2005) Using methods that matter: The impact of reflection, dialogue, and voice. American Journal of Community Psychology 36(3/4): 275-291.

Gulis G, Mulumba JAA, Juma O, et al. (2004) Health status of people of slums in Nairobi, Kenya. Environmental Research 96: 219-227.

Harding A (2002) Nairobi slum life: Into Kibera. Available at: http://news.bbc.co.uk/2/hi/ africa/229737.stm (accessed 28 March 2009).

Israel BA, Schulz AJ, Parker EA, et al. (1998) Review of community-based research: Assessing partnership approaches to improve public health. Annual Review of Public Health 19: 173-202.

Jennings L, Parra-Medina D, Messias D, et al. (2006) Toward a critical social theory of youth empowerment. Journal of Community Practice 14(1/2): 31-55.

Kaime-Atterhog W and Ahlber BM (2007) Are street children beyond rehabilitation? Understanding the life situation of street boys through ethnographic methods in Nakuru, Kenya. Children and Youth Services Review 30: 1345-1354.

Kimutai A (2008) Kenyan slum children find healing in football club. Available at: http:// www.youthsportsny.org/2008/02/kenyan-slum-children-find-heal.html (accessed 28 March 2009).

King N (2004) Using templates in the thematic analysis of text. In: Cassel C and Symon G (eds) Essential Guide to Qualitative Methods in Organizational Research. Thousand Oaks, CA: SAGE, pp. 256-270.

Lee JAB (2001) The Empowerment Approach to Social Work Practice: Building the Beloved Community. New York: Columbia University Press.

Lopez E, Eng E, Robinson N, et al. (2005) Photovoice as a community-based participatory research method. In: Israel B, Eng E, Schulz AJ and Parker D (eds) Methods in Community-Based Participatory Research for Health. San Francisco: John Wiley and Sons, pp. 326-348.

Mitullah W (2003) Urban Slum Reports: The case of Nairobi, Kenya. In: The case of Nairobi, Kenya. The case of Nairobi, reports from UN-HABITAT (the United Nations Human Settlements Programme). Development Planning Unit, University College London. Available at: http://www.ucl.ac.uk/dpu-projects/Global_Report/pdfs/Nairobi.pdf.

Molloy JK (2007) Photovoice as a tool for social justice workers. Journal of Progressive Human Services 18(2): 39-53.

Mwelu Foundation. About. Available at: http://www.mwelu.org/about/. (acessed on 4 March 2014).

Mwelu Foundation and Africalia (2013) Julius Mwelu \& the Mwelu Foundation/Nairobi. Oostkamp, Netherlands: Stichting Kunstboek.

Oliffe JL and Bottorff JL (2007) Further than the eye can see? Photo elicitation and research with men. Qualitative Health Research 17(6): 850-858.

Solomon BB (1976) Black Empowerment: Social Work in Oppressed Communities. New York: Columbia University Press.

Solomon BB (1987) Empowerment: Social work in oppressed communities. Journal of Social Work Practice 2(4): 79-91.

Wallerstein N and Bernstein E (1988) Empowerment education: Freire's ideas adapted to health education. Health Education Quarterly 15(4): 379-394.

Wang C (1999) Photovoice: A participatory action research strategy applied to women's health. Journal of Women's Health 8(2): 185-192.

Wang C and Burris MA (1997) Photovoice: Concept, methodology, and use for participatory needs assessment. Health Education and Behavior 24(3): 369-387. 
Wang CC, Burris MA and Ping XY (1996) Chinese village women as visual anthropologists: A participatory approach to reaching policymakers. Social Science \& Medicine 42(10): 1391-1400.

Wang CC and Redwood-Jones YA (2001) Photovoice ethics: Perspectives from flint photovoice. Health Education \& Behavior 28: 560-571.

Wilson N, Dasho S, Martin AC, et al. (2007) Engaging youth adolescents in social action through photovoice: The Youth Empowerment Strategies (YES!) Project. Journal of Early Adolescence 27(2): 241-261.

Zastrow CH and Kirst-Ashman KK (2010) Understanding human behavior and the social environment. 8th ed. Belmont, CA: Brooks/Cole. 